\title{
PENETAPAN KADAR FLAVONOID EKSTRAK DAUN KELAKAI (Stenochlaena palustris (Burm. F.) Bedd.) DENGAN METODE SPEKTROFOTOMETRI UV-VIS
}

\author{
Eka Siswanto Syamsul ${ }^{1}$, Yana Yunita Hakim ${ }^{2,}$ Henny Nurhasnawati ${ }^{3}$ \\ 1, 2, ${ }^{3}$ Akademi Farmasi Samarinda \\ Jl. Brig Jend A. Wahab Syahranie, Samarinda, Kaltim 75124 \\ Email Korespondensi : eka8382@gmail.com
}

\begin{abstract}
ABSTRAK
Kelakai (Stenochlaena palustris (Burm. F.) Bedd.) merupakan tumbuhan Kalimantan yang berkhasiat obat. Tujuan dari penelitian ini yaitu untuk mengetahui kadar flavonoid ekstrak etanol daun kelakai dengan metode spektrofotometri UVVis.Tahapan penelitian diawali dengan pengumpulan sampel dan determinasi tumbuhan, pembuatan simplisia, pembuatan ekstrak etanol simplisia dengan metode maserasi menggunakan pelarut etanol 70\%, uji skrining fitokimia dan penetapan kadar flavonoid dengan metode spektrofotometri UV-Vis dengan baku pembanding kuersetin. Data dianalisis secara deskriptif. Diperoleh rendemen ekstrak etanol daun kelakai $(22,92 \%)$, penetapan kadar air pada ekstrak kental $(19,71 \%)$, dan kadar flavonoid pada $428 \mathrm{~nm}(2,2159 \pm 0,083 \%)$.
\end{abstract}

Kata kunci : Daun kelakai, Kadar flavonoid, Ekstrak kasar 


\section{ABSTRACT}

Kelakai (Stenochlaena palustris (Burm F.) Bedd.) is a medicinal plant of Borneo. The purpose of this research is to determine the level of flavonoid in crude extract of kelakai leaf by UV-Vis Spectrophotometer. The research was conducted by collection of the kelakai leaves and plant determination. The ethanolic extract of kelakai leaves was collected using macceration methode. The determination of flavonoid level was conducted by UV-Vis Spectrophotometer using quersetin as standard compound. The study showed that the rendemen of crude extract of kelakai leaf was $(22,92 \%)$. The moisture content in viscous extract was $(19,71 \%)$. The level of Flavonoids in extract was $(2,2159 \pm 0,083 \%)$.

Keywords : Leaf kelakai, Flavonoid levels, Crude extract

\section{PENDAHULUAN}

Kelakai merupakan tumbuhan khas lahan rawa yang tumbuh di Kalimantan Selatan. Kelakai juga merupakan makanan favorit sebagian besar masyarakat Kalimantan. Studi empiris dari daun dan batang kelakai muda digunakan oleh masyarakat suku Dayak sebagai suplemen penambah darah, obat awet muda, penambah ASI pada ibu menyusui, obat tekanan darah tinggi, pereda demam dan mengobati sakit kulit seperti gatal dan alergi (Maharani, dkk., 2005).

Kandungan metabolit sekunder yang terkandung dalam daun kelakai yaitu senyawa alkaloid, steroid dan flavonoid (Anggraeni dan Erwin, 2015). Ekstrak air daun kelakai memiliki kandungan total flavonoid yang tinggi dibandingkan dengan tanaman gerunggang dan pasak bumi yang merupakan tanaman obat Kalimantan Selatan (Suhartono, dkk., 2012). Flavonoid merupakan sekelompok besar senyawa polifenol tanaman yang tersebar luas dalam berbagai bahan makanan dan dalam berbagai konsentrasi. Flavonoid mempunyai sifat yang khas yaitu bau yang sangat tajam, sebagian besar merupakan pigmen warna kuning, dapat larut dalam air dan pelarut organik, mudah terurai pada temperatur tinggi (Rahmat, 2009). Flavonoid diyakini dapat menurunkan aterosklerosis dengan menghambat oksidasi LDL (Low Density Lipoprotein) dengan cara menghambat pembentukan radikal bebas (Silalahi, 2006). Sejauh ini belum pernah dilaporkan penelitian mengenai penetapan kadar flavonoid ekstrak etanol daun kelakai (Stenochlaena palustris (Burm. F.) Bedd.) menggunakan metode spektroftometri UV-Vis, sehingga dilakukan penelitian ini.

\section{METODE PENELITIAN}

Penelitian yang dilakukan adalah penelitian non eksperimental. Penelitian dilakukan di Laboratorium Terpadu I dan Laboratorium Terpadu III Akademi Farmasi Samarinda. Tahapan penelitian meliputi pengumpulan sampel, determinasi sampel, pembuatan simplisia, pembuatan ekstrak etanol daun kelakai, identifikasi golongan senyawa kimia dan 
penetapan kadar flavonoid dengan spektrofotometri UV-Vis.

\section{Alat dan Bahan}

Alat yang digunakan dalam penelitian ini adalah Spektrofotometer UV-1800 $\quad\left(\right.$ Shimadzhu $\left.^{\circledR}\right), \quad$ rotary evaporator $\left(\mathrm{IKA}^{\circledR}\right)$, Oven $\left(\right.$ Memmert $\left.^{\circledR}\right)$, maserator $\left(\mathrm{IKA}^{\circledR}\right)$, penangas air, pengaduk elektrik, blender, mikropipet $\left(\right.$ Vitlab $\left.^{\circledR}\right)$, timbangan analitik (Ohaus ${ }^{\circledR}$ ), ayakan mesh 60, seperangkat alat gelas (pyrex ${ }^{\circledR}$ ), corong buchner, rak tabung reaksi, cawan porselen, penjepit tabung, spatel logam dan botol semprot.

Bahan yang digunakan dalam penelitian ini adalah serbuk simplisia daun kelakai, etanol 70\%, kalium asetat 1 $\mathrm{M}$, aluminium klorida 10\%, kuersetin, pereaksi meyer, pereaksi bouchardat, pereaksi dragendorf, $\mathrm{FeCl}_{3} 1 \%, \mathrm{HCl} 2 \mathrm{~N}$, $\mathrm{HCl}$ pekat, $\mathrm{H}_{2} \mathrm{SO}_{4}$ pekat, amil alkohol, kloroform, anhidrida asam asetat, serbuk $\mathrm{Mg}$, aluminium foil, air suling dan kertas saring.

\section{Prosedur Penelitian}

Pembuatan ekstrak etanol daun kelakai

Metode pembuatan ekstrak etanol daun kelakai mengacu pada Depkes RI (2008), dengan modifikasi yaitu serbuk simplisia yang sudah diayak dengan ayakan mesh 60 kemudian ditimbang sebanyak 200 gram, lalu di maserasi dengan etanol $70 \%$, kemudian diaduk menggunakan pengaduk eletrik selama 2 jam. Maserat dan ampas disimpan selama 22 jam dalam wadah tertutup, kemudian disaring menggunakan corong Buchner. Ampas sisa maserasi kemudian diremaserasi lagi dengan etanol $70 \%$ dalam toples kaca dengan pengadukan selama 2 jam dan disimpan selama 22 jam, maserat disaring menggunakan corong Buchner. Maserat hasil maserasi dan remaserasi digabungkan dalam satu wadah dan diuapkan sebagian pelarut menggunakan rotary evaporator kemudian dipekatkan diatas tangas air hingga diperoleh ekstrak kental. Simplisia diremaserasi untuk mendapatkan hasil penyarian yang optimal.

\section{Penetapan kadar air ekstrak etanol daun kelakai}

Penetapan kadar air ekstrak etanol daun kelakai menggunakan metode gravimetri. Prinsip metode gravimetri yaitu menghilangkan kadar air dalam sampel dengan pemanasan menggunakan oven pada suhu $105^{\circ} \mathrm{C}$ agar air yang terikat secara fisik dalam sampel dapat teruapkan sehingga diperoleh berat konstan (Latifah, 2015). Perhitungan kadar air menggunakan rumus sebagai berikut (Dewa dan Mozes, 2014):

$$
\begin{aligned}
& \text { Kadar air }=\frac{b-(c-a)}{b} \times 100 \% \\
& \text { Keterangan: } \\
& a=\text { Berat cawan } \\
& b=\text { Berat sampel } \\
& c=\text { Berat cawan }+ \text { sampel }
\end{aligned}
$$

\section{Uji Golongan Senyawa Metabolit Sekunder}

Uji golongan senyawa metabolit sekunder menggunakan larutan ekstrak etanol daun kelakai yang dibuat dengan cara, ekstrak kental ditimbang sebanyak 0,5 gram, lalu dilarutkan dengan etanol 
sebanyak $10 \mathrm{~mL}$ hingga larut sempurna, kemudian dimasukkan ke dalam labu ukur $100 \mathrm{~mL}$ dan ditambahkan dengan air suling hingga tanda batas (Sapri, dkk., 2014). Larutan tersebut kemudian digunakan untuk melakukan uji senyawa metabolit sekunder, yaitu Uji alkaloid (Pereaksi meyer, Pereaksi bouchardat, Pereaksi dragendorf), uji flavonoid, uji Tannin, uji saponin, uji triterpenoid/steroid (Dewi dkk, 2013; Sapri dkk, 2014).

\section{Penetapan kadar flavonoid}

1. Pembuatan larutan induk (Kuersetin $100 \mathrm{ppm})$

Pembuatan larutan induk dilakukan dengan menimbang kuersetin sebanyak $10 \quad \mathrm{mg}$, kemudian dilarutkan dengan etanol $70 \%$ dalam labu ukur $100 \mathrm{~mL}$. Sehingga diperoleh larutan kuersetin 100 ppm.

2. Pembuatan larutan seri standar kuersetin

Pembuatan larutan standar dengan cara larutan induk dipipet sebanyak 0,$2 ; 0,4 ; 0,6 ; 0,8$ dan $1 \mathrm{~mL}$ masingmasing ke dalam labu ukur $10 \mathrm{~mL}$ menggunakan mikropipet. Volume nya dicukupkan dengan etanol $70 \%$ sampai tanda batas, sehingga diperoleh larutan dengan konsentrasi 2, 4, 6, 8 dan 10 ppm.

3. Pembuatan larutan blanko

Larutan blanko dalam penelitian ini menggunakan etanol $70 \%$ sebanyak $4 \mathrm{~mL}$, kalium asetat $0,2 \mathrm{~mL}$ dan aluminium klorida $0,2 \mathrm{~mL}$, ditambahkan aquades 5,6 $\mathrm{mL}$, kemudian dimasukkan ke dalam labu ukur $10 \mathrm{~mL}$.
4. Penentuan panjang gelombang serapan maksimum ( $\lambda$ maks $)$

Penentuan panjang gelombang maksimum dilakukan dengan cara larutan standar (4 ppm) dipipet 0,5 $\mathrm{mL}$ ke dalam labu ukur $10 \mathrm{~mL}$. Etanol $70 \%$ ditambahkan sebanyak 1,5 mL, aluminium klorida $10 \%$ sebanyak $\quad 0,1 \mathrm{~mL}$, kalium asetat 1 M sebanyak $0,1 \quad \mathrm{~mL}$ dan ditambahkan air suling sebanyak 2,8 $\mathrm{mL}$, dikocok sampai homogen. Absorbansinya diukur pada panjang gelombang 350-500 nm.

5. Pembuatan kurva kalibrasi

Panjang gelombang maksimum diperoleh kemudian dilakukan pembuatan kurva kalibrasi dengan cara larutan standar 2, 4, 6, 8 dan 10 ppm dipipet sebanyak $0,5 \mathrm{~mL}$ dimasukkan ke dalam labu ukur 10 mL kemudian ditambahkan 1,5 mL etanol $70 \%, 0,1 \mathrm{~mL}$ aluminium klorida $10 \%, 0,1$ kalium asetat $1 \mathrm{M}$ dan ditambahkan air suling 2,8 ml, dikocok sampai homogen. Larutan diinkubasi pada suhu kamar selama 30 menit kemudian serapan diukur dengan spektrofotometer UV-Vis pada panjang gelombang maksimum.

6. Pembuatan larutan ekstrak

Pembuatan larutan sampel ekstrak daun kelakai ditimbang sebanyak 10 mg, kemudian dilarutkan dengan 5 $\mathrm{mL}$ etanol $70 \%$ dalam gelas kimia 100 mL. Larutan diaduk menggunakan batang pengaduk, setelah itu dimasukkan ke dalam labu ukur $10 \mathrm{~mL}$. Gelas kimia dibilas dengan etanol $70 \%$ kemudian dimasukkan ke dalam labu ukur hingga tanda batas, sehingga 
diperoleh larutan dengan konsentrasi 1000 ppm. Setelah diperoleh larutan sampel dengan konsentrasi 1000 ppm, dilakukan pengenceran dengan cara dipipet $1 \mathrm{~mL}$ larutan sampel 1000 ppm kemudian dimasukkan ke dalam labu ukur $10 \mathrm{~mL}$ dan ditambahkan dengan etanol $70 \%$ sampai tanda batas sehingga diperoleh larutan dengan konsentrasi $100 \mathrm{ppm}$, lalu dipipet sebanyak 0,5 $\mathrm{mL}$ dan dimasukkan ke dalam labu ukur $10 \mathrm{~mL}$ dan ditambahkan 1,5 mL etanol $70 \%, 0,1 \mathrm{~mL}$ aluminium klorida 10\%, 0,1 mL kalium asetat 1 M dan ditambahkan air suling 2,8 $\mathrm{mL}$ kemudian kocok sampai homogen. Larutan diinkubasi pada suhu kamar selama 30 menit. Serapan diukur dengan spektrofotometer UV-Vis pada panjang gelombang maksimum. Kemudian dilakukan perhitungan kadar flavonoid menggunakan rumus metode Chang, dkk., (2002).

Kandungan Flavonoid $(\%) \quad=$ $\frac{\mathrm{C} \times \mathrm{V} \times \mathrm{Fp} \times 10^{-3}}{\mathrm{~m}} \times 100 \%$

Keterangan :

$\mathrm{C}=$ Kesetaraan Kuersetin $(\mathrm{mg} / \mathrm{L})$

$\mathrm{V}=$ Volume total ekstrak etanol $(\mathrm{mL})$

$\mathrm{Fp}=$ Faktor Pengenceran

$\mathrm{m}=$ Berat sampel $(\mathrm{mg})$

\section{Analisis Data}

Data yang dikumpulkan pada penelitian ini adalah data deskriptif berdasarkan nilai kadar flavonoid ekstrak etanol daun kelakai dengan menggunakan rumus yaitu $y=b x+a$ dimana $y$ adalah absorbansi, $b$ adalah slope, $x$ adalah konsentrasi dan $a$ adalah intersep, ditentukan dengan cara menginterpolasikan data absorbansi sampel yang diperoleh dari alat spektrofotometer sehingga dapat diketahui konsentrasinya dan disajikan dalam bentuk grafik.

\section{HASIL DAN PEMBAHASAN}

\section{Penetapan Kadar Air Ekstrak Etanol} Daun Kelakai

Penetapan kadar air ekstrak etanol daun kelakai dilakukan menggunakan metode gravimetri. Prinsip metode gravimetri yaitu menghilangkan kadar air dalam sampel dengan pemanasan menggunakan oven pada suhu $105^{\circ} \mathrm{C}$ agar air yang terikat secara fisik dalam sampel dapat teruapkan sehingga diperoleh berat konstan (Latifah, 2015).

Penetapan kadar air ekstrak etanol daun kelakai bertujuan untuk mengetahui kadar air yang terkandung pada ekstrak yang digunakan. Penentuan kadar air ini sangat penting dilakukan karena menentukan kesegaran dan daya tahan dari suatu ekstrak. Kadar air untuk ekstrak cair lebih dari 30\%, ekstrak kental 5-30\% dan ekstrak kering kurang dari 5\% (Voigt, 1994). Hasil penetapan kadar air yang diperoleh dari ekstrak kental yaitu $19,71 \%$, hasil yang diperoleh telah memenuhi persyaratan yang telah ditetapkan dimana kadar air yang besar dapat menyebabkan pertumbuhan mikroba, karena air merupakan media pertumbuhan mikroba (Supomo, dkk., 2016).

\section{Skrining Fitokimia Ekstrak Etanol} Daun Kelakai

Skrining fitokimia bertujuan untuk mengetahui golongan senyawa yang 
terkandung dalam ekstrak. Hasil uji skrining fitokimia dapat dilihat pada tabel 1 .

Hasil skrining fitokimia dari penelitian yang dilakukan diketahui bahwa ekstrak etanol daun kelakai mengandung senyawa alkaloid, flavonoid, tanin, saponin dan triterpenoid. Penelitian Anggraeni dan Erwin (2015) juga menunjukkan bahwa kandungan metabolit sekunder yang terkandung di dalam daun kelakai yaitu senyawa alkaloid, steroid dan flavonoid. Perbedaan tersebut dikarenakan faktor lingkungan seperti iklim, cahaya, suhu udara, kelembaban, lingkungan perakaran (sifat fisika dan kimia tanah) dan ketersediaan air di dalam tanah memiliki pengaruh terhadap hasil metabolisme sekunder tumbuhan (Mahatriny, dkk., 2014).

\section{Penetapan Kadar Flavonoid Ekstrak} Etanol Daun Kelakai

Penetapan kadar flavonoid ekstrak etanol daun kelakai dilakukan dengan kolorimetri dengan aluminium klorida. Analisis dilakukan dengan pembuatan larutan induk kuersetin, larutan seri standar, penentuan panjang gelombang, penentuan absorbansi kadar senyawa flavonoid dan kalibrasi hasil pengukuran dengan standar yang sudah dibuat.

Kuersetin digunakan sebagai larutan induk karena kuersetin dapat membentuk kompleks antara $\mathrm{AlCl}_{3}$ dengan gugus keto pada atom C-4 dan juga dengan gugus hidroksil pada atom C-3 atau C5 yang bertetangga dari flavon dan flavonol (Chang, dkk., 2002), setelah dibuat larutan induk kuersetin selanjutnya dibuat serangkaian larutan standar 2, 4, 6, 8 dan 10 ppm dari larutan induk kuersetin 100 ppm. Blanko pada penelitian ini yaitu etanol $70 \%, \mathrm{AlCl}_{3} 10 \%$, kalium asetat 1 M dan air suling. Larutan kemudian diinkubasi selama 30 menit bertujuan agar reaksi berjalan sempurna, sehingga memberikan intensitas warna yang maksimal (Azizah, dkk., 2014)

Tabel 1. Hasil uji skrining fitokimia ekstrak etanol daun kelakai

Keterangan :

\begin{tabular}{|c|l|c|}
\hline No. & \multicolumn{1}{|c|}{ Uji Fitokimia } & Hasil pengamatan \\
\hline 1. & Alkaloid & $(+)$ \\
\hline \multirow{2}{*}{} & Meyer & $(+)$ \\
\cline { 2 - 3 } & Bouchardat & $(+)$ \\
\cline { 2 - 3 } & Dragendorf & $(+)$ \\
\hline 2. & Flavonoid & $(+)$ \\
\hline 3. & Tanin & $(+)$ \\
\hline 4. & Saponin & $(+)$ \\
\hline 5. & Steroid & $(-)$ \\
\hline 6. & Triterpenoid & $(+)$ \\
\hline
\end{tabular}

$(+)=$ terdapat senyawa kimia

$(-)=$ tidak terdapat senyawa kimia 
Penambahan alumunium klorida bertujuan untuk membentuk kompleks dengan kuersetin (Indrayani, 2008), sedangkan penambahan kalium asetat pada penelitian ini untuk menstabilkan pembentukan kompleks antara $\mathrm{AlCl}_{3}$ dengan kuersetin (Wahyulianingsih, 2016). Hasil pengukuran panjang gelombang menggunakan larutan standar 4 ppm diperoleh panjang gelombang maksimum yaitu $428 \mathrm{~nm}$. Panjang gelombang maksimum tersebut kemudian digunakan untuk mengukur serapan kurva kalibrasi dan sampel ekstrak (Azizah, dkk., 2014). Pengukuran kurva kalibrasi bertujuan untuk mengetahui persamaan garis linier. Panjang gelombang yang didapat telah sesuai dengan panjang gelombang yang telah ditetapkan yaitu panjang gelombang kompleks dari 15 standar dengan aluminium klorida menunjukkan bahwa kompleks yang terbentuk oleh flavonol dengan C-3 dan C-5 kelompok hidroksil, seperti galangin, morin dan kaempferol, serta yang memiliki kelompok ekstra orto-dihidroksil seperti rutin, kuersetin, kuercitrin dan miricetin, maksimal absorbansi pada 415 - 440 nm (Chang, dkk., 2002).

Hasil pengukuran absorbansi standar pada panjang gelombang 428 $\mathrm{nm}$ diperoleh data yang dapat dilihat pada tabel 2 .

Tabel 2. Penentuan absorbansi larutan standar kuersetin

\begin{tabular}{|c|c|c|}
\hline No. & Konsentrasi $(\mathrm{ppm})$ & Absorbansi \\
\hline 1. & 2 & 0,0263 \\
\hline 2. & 4 & 0,0398 \\
\hline 3. & 6 & 0,0517 \\
\hline 4. & 8 & 0,0651 \\
\hline
\end{tabular}

Hasil penentuan absorbansi larutan standar tersebut dapat dilihat bahwa sesuai dengan hukum Lambert-Beer yaitu konsentrasi berbanding lurus dengan absorbansi dimana semakin tinggi nilai absorbansi akan berbanding lurus dengan konsentrasi zat yang terkandung didalam suatu sampel (Neldawati, dkk., 2013). Hasil pengukuran absorbansi larutan standar pada berbagai konsentrasi kurva kalibrasi, diperoleh persamaan regresi linier yaitu $y=$ $0,006045 x+0,01513$ dengan nilai koefisien kolerasi $(r)=0,9979$. Nilai r yang mendekati 1 menunjukkan kurva kalibrasi linier dan terdapat hubungan antara konsentrasi larutan kuersetin dengan nilai serapan (Azizah, dkk., 2014).

Penetapan kadar flavonoid ekstrak ekstrak etanol dilakukan dengan 4 kali pengulangan untuk mendapatkan keakuratan data dan didapatkan hasil yang terdapat pada tabel 3 . 
Tabel 3. Kadar flavonoid ekstrak etanol daun kelakai

\begin{tabular}{|c|c|c|c|}
\hline No. & Sampel & Kadar flavonoid (\%) & Rata-rata (\%) \pm SD \\
\hline 1. & Replikasi 1 & 2,2945 & \\
\hline 2. & Replikasi 2 & 2,1290 & \multirow{2}{*}{$2,2159 \pm 0,083$} \\
\hline 3. & Replikasi 3 & 2,1621 & \\
\hline 4. & Replikasi 4 & 2,2779 & \\
\hline
\end{tabular}

Penelitian Suhartono, dkk., (2012) menemukan bahwa kadar flavonoid yang terdapat dalam ekstrak air daun kelakai memiliki rata-rata kadar flavonoid sebesar $14,5 \mu \mathrm{g} / \mathrm{mL} \pm 0,7$ atau $0,00145 \pm 0,00007 \%$. Hasil penelitian menunjukkan bahwa kadar flavonoid yang terdapat dalam ekstrak etanol daun kelakai memiliki rata-rata kadar flavonoid sebesar 2,2159 $\pm 0,083 \%$. Ekstrak etanol menghasilkan kadar flavonoid yang lebih tinggi dibandingkan dengan ekstrak air, hal ini menunjukkan bahwa pelarut etanol dapat mengekstrak senyawa flavonoid (Ukieyanna, 2012).

\section{SIMPULAN}

Berdasarkan penelitian yang telah dilakukan dapat diketahui kadar flavonoid pada ekstrak etanol daun kelakai sebesar 2,2159 \pm $0,083 \%$.etanol daun kelakai sebesar 2,2159 $\pm 0,083 \%$.

\section{UCAPAN TERIMAKASIH}

Terima Kasih kepada LPPM Akademi Farmasi Samarinda atas pendanaan pada penelitian ini.
DAFTAR PUSTAKA

Anggraeni, D.S., dan Erwin. 2015.

"Uji Fitokimia dan Uji

Toksisitas (Brine Shrimp

Lethality Test) Ekstrak Daun

Kelakai (Stenochlaena

palustris)". Prosiding Seminar

Tugas Akhir. Hal: 71-75.

Azizah, D.N., Endang, K., dan Fahrauk, F. 2014. "Penetapan Kadar Flavonoid Metode $\mathrm{AlCl}_{3}$ Pada Ekstrak Metanol Kulit Buah Kakao (Theobroma cacao L.) Vol. 2 (2): 45-49.

Chang, C, Ming, H., Hwei, M., and Chern J. 2002. "Estimation of Total Flavonoid Content in Propolis by Two Complementary Colorimetric Methods". Journal of Food and Drug Analysis. Vol. 10 (3): 1181.

Dewa, R.P., dan Mozes, S.Y.R. 2014. "Pengaruh Perendaman $\mathrm{KOH}$ 5\% Terhadap Rumput Laut 
Sebagai Bahan Baku Produk Gel Pengharum Ruangan". Biopropal Industri. Vol. 5 (2): 53-60.

Dewi, I.D.A.D.Y., Astuti, K., dan Wardani, N.K. 2013. "Identifikasi Kandungan Kimia Ekstrak Kulit Buah Manggis (Gracinia mangostana L.)". Jurnal Farmasi Udayana. Vol. 2 (4): 13-18.

Indrayani, S. 2008. "Validasi Penetapan Kadar Kuersetin Dalam Sediaan Krim Secara Kolorimetri dengan Pereaksi $\mathrm{AlCl}_{3}$ ". Skripsi. Yogyakarta: Universitas Sanata Dharma. Hal: $7,8,25$.

Latifah. 2015. "Identifikasi Golongan Senyawa Flavonoid dan Uji Aktivitas Antioksidan Pada Ekstrak Rimpang Kencur Kaempferia galanga L. Dengan Metode DPPH (1,1-difenil-2pikrilhidrazil)". Skripsi. Malang: Jurusan Kimia. Universitas Islam Negeri Maulana Ibrahim. Hal: 38.

Maharani, D.M., Siti, N.H., dan Haiyinah. 2005. "Studi Potensi Kelakai (Stenochlaena palustris (Burm.f) Bedd), Sebagai Pangan Fungsional”. PKM Penelitian. Jurusan Budidaya Pertanian. Banjarbaru: Univ Lambung Mangkurat. 13 (1). Hal: 1-13.

Mahatriny, N.N., Payani, N.P.S., Oka, I.B.M., dan Astuti, K.W. 2014. "Skrining Fitokimia Ekstrak Etanol Daun Pepaya (Carica papaya L.) yang diperoleh dari Daerah Ubud, Kabupaten Gianyar, Bali”. Jurnal Farmasi Udayana. Vol. 3 (1): 8-13.
Neldawati, Ratnawulan dan Gusnedi. 2013. "Analisis Nilai Absorbansi dalam Penentuan Kadar Flavonoid untuk Berbagai Jenis Daun Tanaman Obat". Pillar Of Physics. Vol. 2. Hal: 76-83.

Rahmat, H. 2009. "Identifikasi Senyawa Flavonoid Pada Sayuran Indigenous Jawa Barat". Skripsi. Bogor: Fakultas Teknologi Pertanian Institut Pertanian. Hal: 4,20.

Sapri, Ana, F., dan Rizka, N., 2014. "Pengaruh Ukuran Serbuk Simplisia Terhadap Rendemen Ekstrak Etanol Daun Sirsak (Annona muricata L.) Dengan Metode Maserasi”. Prosiding Seminar Nasional Kimia. Akademi Farmasi. Hal: 1-4.

Silalahi, J. 2006. Makanan Fungsional. Cetakan ke 6. Yogyakarta: Penerbit Kanisius. Hal: 121.

Suhartono, E., Ella, V., Mustaqim A.R., Imam S.G., Muhammad F.R., and Danny I. 2012. "Total flavonoid and Antioxidant Acivity of Some Selected Medicinal Plants in South Kalimantan of Indonesia". Univ Lambung Mangkurat. Procedia APCBEE. Vol. 4. Hal: 235-239.

Supomo., Risa, S., dan Risaldi, J. 2016. "Karakterisasi dan Skrining Fitokimia Daun Kerehau (Callicarpa longifolia 
Lamk.)". Jurnal Kimia Mulawarman. Vol. 13 (2): 89-96.

Ukieyanna, E. 2012. "Aktivitas Antioksidan, Kadar Fenolik, dan Flavonoid Total Tumbuhan Suruhan (Peperomia pellucida L. Kunth)". Skripsi. Bogor: Institut Pertanian Bogor. Hal: 9.

Voigt R. 1994. Buku Pelajaran Teknologi Farmasi. Edisi 5. Diterjemahkan oleh Soendani Noerono S. Gadjah Mada University Press. Yogyakarta. Hal: 577.

Wahyulianingsih, Selpida, H. dan Abdul, M. 2016. "Penetapan Kadar Flavonoid Total Ekstrak Daun Cengkeh (Syzygium aromaticum (L.) Merr \& Perry)". Jurnal Fitofarmaka Indonesia, Vol. 3 (2): 188-193. 